\title{
Prognostic and predictive value of c-erbB2 overexpression in osteogenic sarcoma
}

\author{
Vasishta Rakesh \\ Kumar, *Gupta Nalini, \\ Kakkar Nandita, \\ **Sharma S.C \\ Dept of Histopathology, \\ *Cytopathology and \\ **Radiotherapy, Post \\ Graduate Institute of \\ Medical Education and \\ Research, Chandigarh, \\ India - 160012. \\ For correspondence: \\ R K Vasishta, \\ Department of \\ Histopathology \\ Postgraduate Institute of \\ Medical Education and \\ Research, \\ Chandigarh-160 012, \\ India, E-mail: \\ nalini203@rediffmail.com
}

\section{ABSTRACT}

Background: Osteogenic sarcoma (OS) is a highly malignant tumor of the bone. There are few reports in the literature regarding determination of c-erb B-2 (HER-2/neu) expression in cases of OS and also the results are quite variable.

Aim: The present study was undertaken to correlate the expression of c-erbB2 with the survival of patients of OS.

Settings and Design: A retrospective study of cases of OS, in which the expression of c-erbB-2 by immunohistochemistry (IHC) was studied and correlated with the survival rate of the patients.

Materials and Methods: Out of a total of 49 cases, proper follow up data in the form of total and disease free survival was available in only 20 cases. $\mathrm{IHC}$ for c-erb-B2 was carried out in these 20 cases.

Results: The staining pattern was as follows: no staining in 3 cases, $1+$ in 5 cases, $2+$ in 3 cases, $3+$ in 3 cases and $4+$ cytoplasmic positivity in 6 cases.

Statistical analysis: Spearman rank correlation test was used to correlate the intensity of cytoplasmic staining of c-erbB-2 with survival rate of the patients, response to chemotherapy and metastasis.

Conclusions: Previous studies have shown that c-erbB-2/ HER-2 is an independent prognostic factor in osteogenic sarcoma, but in the present study, its expression was not seen to be correlating with survival rate of the patients. Therefore, further studies are needed to reach a consensus regarding the reliability of c-erbB-2 as an independent prognostic factor in OS.

KEY WORDS: Osteogenic sarcoma, c-erbB-2, Immunohistochemistry

\section{INTRODUCTION}

Osteogenic sarcoma (OS) is the most frequent and highly malignant bone tumor, seen during second and third decade of life. ${ }^{[1]}$ Several oncogenes and tumor suppressor genes are reported to be involved in the oncogenesis of OS. Although survival rate increased up to $60-70 \%$ within the last 20 years, the problem of non-response to chemotherapy remains. There are many factors thought to have an influence on prognosis of OS, but their exact role is still controversial. The overexpression of cerbB-2 (also called neu or HER2) proto-oncogene has been studied and correlated with poor survival rate in various human tumors especially breast carcinomas Little is known about the expression of c-erbB-2 in sarcomas, ${ }^{[2]}$ especially OS and only few reports are available in the literature, that to showing controversial results. Therefore, in the present study, we studied 20 cases of os for expression of c-erbB-2 (HER-2/neu) and correlated the expression with the survival rate of patients.

\section{MATERIALS AND METHODS}

The present study was a retrospective study (19972003) in the Department of histopathology. A total of 49 cases of OS were retrieved from surgical pathology files. Clinical details of cases were reviewed for age, sex, clinical presentation, pathological diagnosis and treatment. Out of these 49 cases, proper follow up data was available in only 20 cases. Only pretreatment tissues from the primary tumor were used, except for one case, which had recurrence. No metastases were evaluated. The follow up data was collected from the radiotherapy files of these cases and their total as well as disease free survival was noted. Histological sections were obtained from formalin fixed paraffin embedded tissues. The sections were restained and all the cases were reviewed by a pathologist to confirm the diagnosis of OS. For immunohistochemistry (IHC), a representative blocks with adequate viable tumor (avoiding areas of necrosis) were chosen. Monoclonal antibody 
against c-erbB-2/HER-2/Neu Ab-12 (clone CB 11) was obtained from Neomarkers. 3-4 $\mu \mathrm{m}$ thick sections were cut from tissue blocks, placed on pretreated glass slides, dried at $37^{\circ} \mathrm{C}$ overnight and then at $60^{\circ} \mathrm{C}$ for 30 minutes. Sections were dewaxed and rehydrated through graded alcohols. Inhibition of endogenous peroxidase was done by treatment for 30 minutes with $3 \%$ hydrogen peroxide in methanol. After washing, blocking was done with normal serum and 4 rinses with buffer were given. The slides were placed in microwave for 3 cycles for 4 minutes each and then these were allowed to cool at room temperature for 90 minutes. The slides were incubated with primary antibody at room temperature for 90 minutes followed by washing ( 3 times for 5 minutes each).Then slides were incubated with secondary antibody for 30 minutes followed by Avidin- Biotin reagent for 30 minutes and then DAB (Diaminobenzidine). The sections were again placed in running tap water, dehydrated in a graded series of alcohols, cleared in 2 changes of xylene and mounted. Sections of breast carcinoma with known over expression of HER- 2/neu oncogene served as the positive control. The positivity was scored independently by two histopathologists. The IHC positivity was scored as:

$0=$ no staining

$1+=1-25 \%$ positive cells

$2+=26-50 \%$ positive cells

$3+=51-75 \%$ positive cells

$4+=76-100 \%$ positive cells.

\section{RESULTS}

In a total of 20 cases, the age ranged from 8 years to 38 years with male to female ratio of 3.2: 1.13 cases were amputation specimens and 7 cases were biopsies from the tumors. All cases were high grade conventional OS [Figure 1], except one case of telangiectatic variant of OS. Six cases on histopathology were rich in osteoclastic type of giant cells [Figure 2]. The primary site of involvement was lower end of femur in 11 cases and proximal end of tibia in 5 cases. Other sites involved were maxilla, fibula, chest wall and sacrum (one case each). One case had lung metastasis at the time of presentation. Disease free survival in these 20 cases varied from one month to $3 \frac{1}{2}$ years.

Pleural effusion, lung metastasis, cervical and retroperitoneal lymphadenopathy and bone metastasis were seen in four, three, three and two cases, respectively. Complete

Table 1: Showing poor correlation between cytoplasmic positivity of c-erbB-2 and disease free survival time of patients of osteogenic sarcoma

\begin{tabular}{ccc}
\hline Positivity score & $\begin{array}{c}\text { Total no. } \\
\text { of cases }\end{array}$ & $\begin{array}{c}\text { Disease free } \\
\text { survival in months }\end{array}$ \\
$0+$ & 3 & $9,2,8$ \\
$1+$ & 5 & $8,6,24,26,9$ \\
$2+$ & 3 & $7,6,11$ \\
$3+$ & 3 & $10,16,42$ \\
$4+$ & 6 & $8,11,30,1,4,6$ \\
\hline
\end{tabular}

membranous positivity was not seen in any of the cases. The staining pattern was as follows: no staining in 3 cases, $1+$ (focal cytoplasmic positivity in $1-25 \%$ cells) in 5 cases, $2+$ in 3 cases, $3+$ in 3 cases and $4+$ cytoplasmic positivity in 6 cases [Figure 3]. Osteoclastic type giant cells also showed strong cytoplasmic positivity in all six cases. The expression of c-erbB-2 was correlated with the disease free survival time of patients of OS. The intensity of cytoplasmic staining of monoclonal antibody against c-erbB-2/HER- 2/Neu Ab-12 (clone $C B$ 11) did not correlate with survival rate of the patients, response to chemotherapy and metastasis as shown in [Table 1]. Spearman rank correlation test was applied and $\mathrm{p}$ value calculated was 0.692 , which was not significant.

\section{DISCUSSION}

Osteogenic sarcoma (OS) is the most frequent primary malignant bone tumor, exclusive of hematopoietic malignancy. It usually occurs in patients between 10 and 25 years of age. Most OS arising denovo are located in the

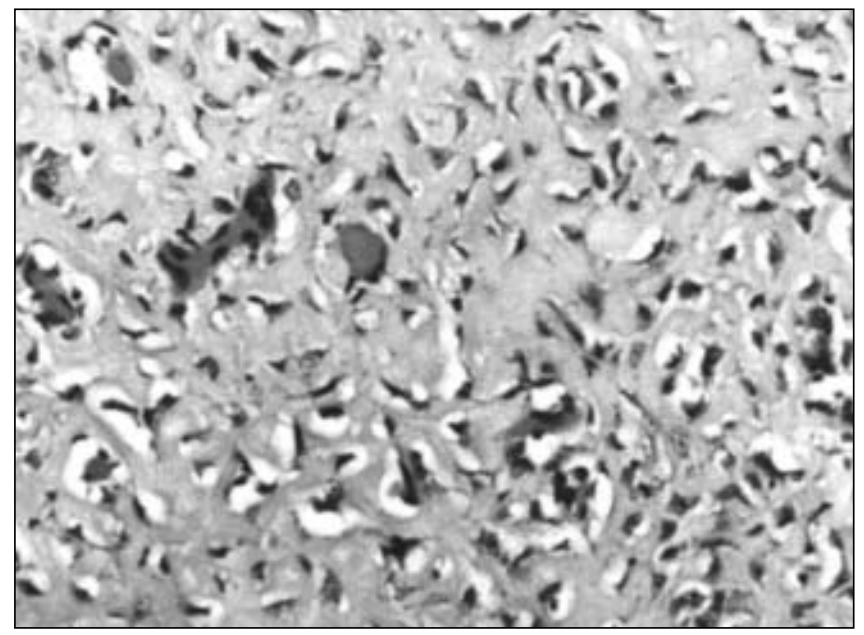

Figure 1: Microphotograph showing osteoid production by tumor cells in a case of osteogenic sarcoma (H\&E, X250)

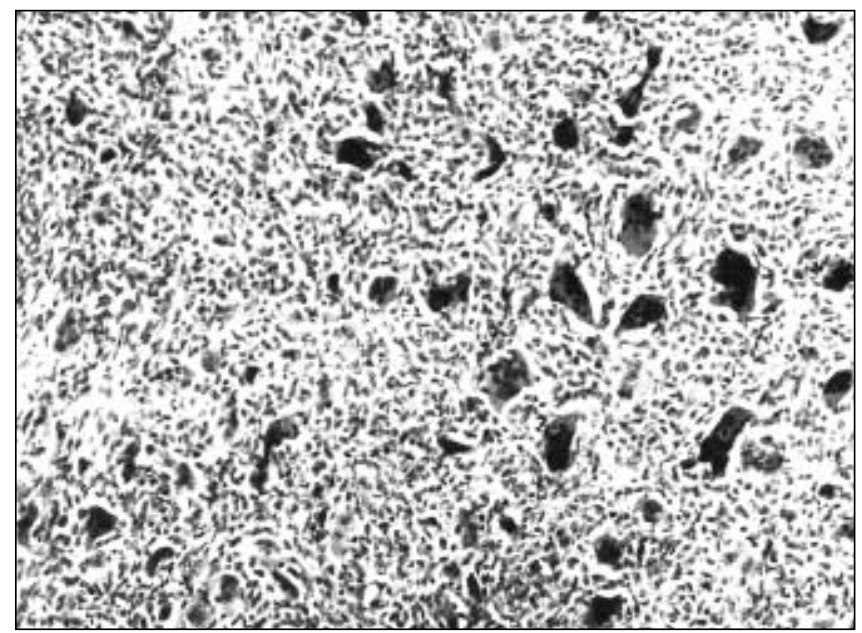

Figure 1: Microphotograph showing a case of giant cell rich variant of osteogenic sarcoma (H\&E, X125) 
metaphyseal area of the long bones, particularly, lower end of femur, the upper end of tibia and the upper end of the humerus. Metastasis occurs most commonly to lungs (98\%), other bones (37\%), pleura (33\%), and heart $(20 \%) \cdot{ }^{[3]} 5$ - year survival is approximately $50-70 \%{ }^{[4]}$

Various prognostic factors are tumor size, response to chemotherapy, post chemotherapy tumor necrosis, serum elevation of alkaline phosphatase levels. Several oncogenes and tumor suppressor genes are reported to be involved in the oncogenesis of OS as c-myc, c-raf, c-myb, c-met, c-sis, cgli, $\mathrm{RB}$ and $\mathrm{p} 53^{[5-10]}$ Amplification of $\mathrm{mdm}-2$ gene has been correlated with poor prognosis in OS. ${ }^{[1]}$

c-erb B-2 (HER-2/neu) proto-oncogene is located on human chromosome 17 at q21. ${ }^{[12]}$ It encodes a 185- kilo dalton transmembrane glycoprotein that shows significant structural similarity to epidermal growth factor receptor. ${ }^{[13]}$ The neu differentiation factor (NDF) stimulates the kinase activity of erb B-2. It however does not directly interact with erbB-2. Instead it interacts with a heterodimer of erb B-2 and the related receptor such as erbB3 or erbB4. ${ }^{[14]}$

Elevated expression of erbB-2 family members have been reported in a variety of human tumors, particularly breast carcinomas. In the majority of studies, erb B-2 (HER-2/neu) over expression was found to be correlated with decreased survival. ${ }^{[15]}$ Most recent series failed to find any prognostic relation between HER-2/neu overexpression and disease outcome. Such conflicting results can be explained by the low patient number evaluated in some studies and different methods used to determine c-erbB-2 (HER-2/neu) status, including solid matrix- blotting, Immunohistochemistry (IHC), fluorescent in situ hybridization (FISH) and enzyme linked immunoadsorbent assay (ELISA). Immunohistochemistry (IHC) is a preferred method, as it can be performed easily on a routine basis and it is used to identify proteins expressed

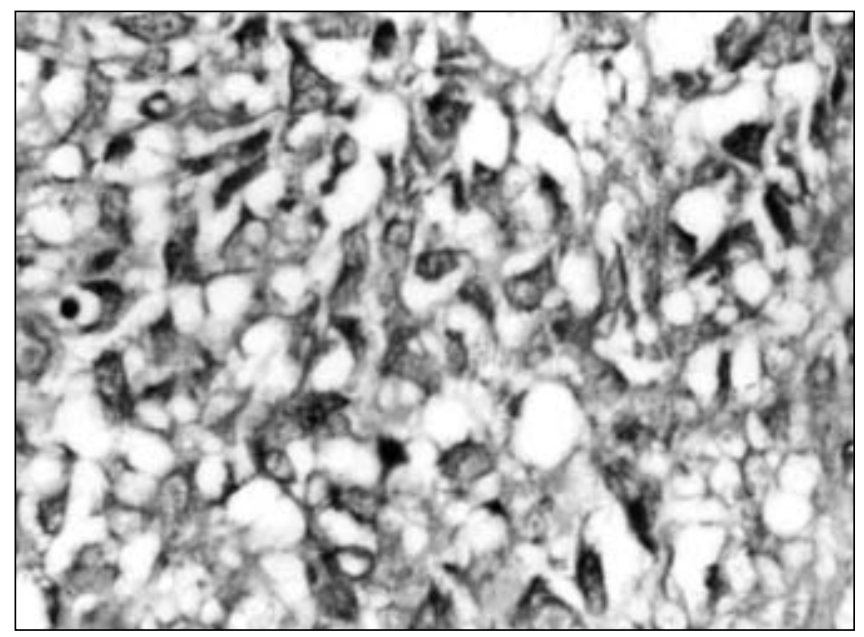

Figure 3: Microphotograph showing 4+ cytoplasmic positivity of cerbB-2 in tumor cells of a case of osteogenic sarcoma (Immunostain, X250) by fixed cells in paraffin embedded tissue sections. ${ }^{[16]}$

Normal bone shows very little expression of c-erbB-2. ${ }^{[17]}$ There are very few reports in the literature regarding determination of c-erbB-2 (HER-2/neu) expression in cases of OS and in these few reports also the results are quite variable. Onda ${ }^{[4]}$ et al in 1996 studied expression of c-erbB-2 in the tumors of 26 patients with conventional OS by immunoblot analysis and confirmed by IHC studies (CB11 antibody). They documented c-erbB-2 expression in 11 of 26 OS cases (42\%) and expression of c-erbB-2 was strongly correlated with early pulmonary metastasis and poor survival rate for the patients. They suggested that c-erbB-2 plays a significant role in aggressive tumor growth and in the promotion of metastatic potential in OS. Gorlick ${ }^{[18]}$ et al in 1999 analyzed expression of c-erbB-2 (HER-2/neu) in 47 patients of OS by IHC methods. They documented high levels of HER-2/neu expression in 20/47 OS samples (42.6\%). High levels of c-erbB-2 were seen in patients with metastatic disease at presentation and at the time of relapse. They suggested that HER-2/neu should be evaluated prospectively as a prognostic indicator.

Zhou and colleagues ${ }^{[19]}$ reported a correlation between cytoplasmic staining of HER-2/neu and increased risk of pulmonary metastasis in OS. Maitra et al ${ }^{[20]}$ in 2001, studied 18 high grade OS by IHC and FISH analysis. Overexpression of erb B-2 was not observed in their study.

Kilpatrick et al in $2001^{[21]}$ also studied expression of HER-2/ neu oncogene in 41 cases of OS by IHC method. Complete membranous positivity was not seen in any of these cases and cytoplasmic positivity was observed in most of the cases irrespective of their subtype/grade. The expression was not associated with response to preoperative chemotherapy or disease progression.

Although IHC staining appears to be the predominant method for determining HER-2/neu oncogene overexpression, the results may be substantially affected by technical issues, including fixation, duration and prolonged storage. Also, type and sensitivity of the antibodies also differ. In the present study, membranous positivity of the expression of osteosarcoma was not seen. Cytoplasmic positivity also was not seen to correlate with response to chemotherapy, metastasis and disease free survival. Therefore, we recommend more prospective studies with larger number of cases to establish the role of c-erbB-2, as an independent prognostic factor in human OS.

\section{REFERENCES}

1. Trieb K, Lehner R, Stuling T, Sulzbacher I, Shroyer KR. Survivin expression in human osteosarcoma is a marker for survival. Eur J Surg Oncol 2003;29:379-82.

2. Dujin Z, Hector B, Yokota J, Yamammoto T, Martin JC. Association of multiple copies of the c-erbB-2 oncogene with spread of breast 
cancer. Cancer Res 1987;47:6123-5.

3. Uribe-Botero G, Russell WO, Sutow WW, Martin RG. Primary osteosarcoma of bone. A clinicopathologic investigation of 243 cases, with necropsy studies in 54. Am J Clin Pathol 1977;67:42735.

4. Onda M, Matsuda S, Higaki S, Iijima T, Fukushima J, Yokokura A, et al. ErbB-2 expression is correlated with poor prognosis for patients with osteosarcoma. Cancer 1996;7:71-8.

5. Yokota J, Yokota YT, Battifora H, Fevre CL, Cline MJ. Alteration of myc, myb and $\mathrm{H}$-ras proto-oncogenes in cancers are frequent and show clinical correlation. Science 1986;231:261-5.

6. Bogenmann E, Moghadam H, DeClerck YA, Mock A. C-MYC amplification and expression in newly established human osteosarcoma cell lines. Cancer Res 1987;47:3808-14.

7. Roberts WM, Douglass EC, Peiper SC, Houghton PJ, Look AT. Amplification of the gli gene in childhood sarcoma. Cancer Res 1989;49:5407-13.

8. Graves DT, Owen AJ, Barth RK, Tempst P, Winoto A, Fors L, et al. Detection of c-sis transcripts and synthesis of PDGF like proteins by human osteosarcoma cells. Science 1984;226:972-4.

9. Friend SH, Bernards R, Rogelj S, Weinberg RA, Rapaport JM, Albert $\mathrm{DM}$, et al. A human DNA segment with properties of the gene that predisposes to retinoblastoma and osteosarcoma. Nature 323:643-6, 1986.

10. Miller C, Aslo A, Tsay C, Slamon D, Ishizaki K, Toguchida J, et al. Frequency and structure of p53 rearrangements in human osteosarcoma. Cancer Res 1990;50:7950-4.

11. Ladanyi M, Cha C, Lewis R, Jhanwar SC, Huvos AG, Healey JH. MDM2 gene amplification in metastatic osteosarcoma. Cancer Res 1993;53:16-8.

12. Fukushige $\mathrm{S}$, Matsubara K, Yoshida M, Sasaki M, Suzuki T, Semba $\mathrm{K}$, et al. Localisation of a novel $\mathrm{v}$-erbB-related gene, c-erbB-2 on
Vasishta R, et al.: Prognostic and predictive value of c-erbB2

human chromosome- 17 and its amplification in a gastric cancer cell line. Mol cell Biol 1986;6:955-8.

13. Yamamoto T, Ikawa S, Akiyama T, Semba K, Nomura N, Miyajima $\mathrm{N}$, et al. Similarity of protein encoded by the human c-erbB-2 gene to epidermal growth factor receptor. Nature 1986;319:2304.

14. Peles E, Ben-Levy R, Tzahar E, Liu N, Wen D, Yarder Y. Cell- type specific interaction of neu differentiation factor (NDF/ heregulin) with neu/HER-2 suggests complex ligand-receptor relationships. EMBOJ 1993;12:961-71.

15. Wright C, Angus B, Nicholson S, Sainsbury RC, Cairns J, Gullick WJ, et al. Expression of c- erbB-2 oncoprotein: a prognostic indicator in human breast cancer. Cancer Res 1989;49:2087-90.

16. Selvaggi G, Scagliotti GV, Torri V, Novello S, Leonardo E, Cappia S, et al. HER-2/neu overexpression in patients with radically resected nonsmall cell lung carcinoma. Cancer 2002;94:2669-74.

17. Press MF, Cordon-Cardo C, Slamon DJ. Expression of the HER-2/ neu protooncogene in normal human adult and fetal tissues. Oncogene 1990;5:953-62.

18. Gorlick R, Huvos AG, Aledo A, Beardsley GP, Healey JH, Meyers PA. Expression of HER2/erbB-2 correlates with survival in osteosarcoma. J Clin Oncol 1999;17:2781-8.

19. Zhou H, Randall LR, Goldsby R, Smith L, Coffin CM. HER-2/neu staining in osteosarcoma: association with increased risk of metastasis. Mod Pathol 2001;14:19A.

20. Maitra A, Wanzer DM, Saboorian H, Weinberg AG, Ashfaq R. Amplification of the Her-2/neu oncogene is uncommon in pediatric osteosarcomas. Mod Pathol 2001;14:4.

21. Kilpatrick SE, Geisinger KR, King TS, Sciarrotta J, Ward WG, Gold $\mathrm{SH}$, et al. Clinicopathologic analysis of HER-2/neu immunoexpression among various histologic subtypes and grades of osteosarcoma. Mod Pathol 2001;14:1277-83. 